\title{
Cytomegalovirus transmission from breast milk in premature babies: does it matter?
}

\section{P Bryant, C Morley, S Garland, N Curtis}

There is evidence that CMV is commonly present in breast milk and is often transmitted to babies. CMV infection acquired postnatally can cause serious disease in very premature babies. Interventions to remove CMV from breast milk are possible but may damage other important constituents.

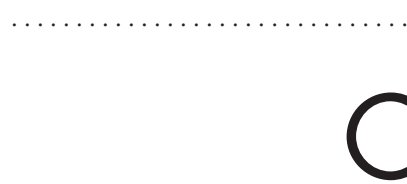

$\overbrace{}^{t}$ ngenital cytomegalovirus (CMV) infection from primary maternal CMV infection is a well recognised cause of perinatal morbidity and mortality. ${ }^{1}$ In contrast, the postnatal transmission of CMV from mother to baby by non-transplacental routes, such as breast milk, has been less well studied. Postnatal primary CMV infection is not usually associated with significant disease in term babies. This is because in most cases the source of infection is maternal and therefore the baby is protected by passively acquired CMV antibodies. In contrast, very premature babies do not have this protection, as transfer of antibodies occurs principally after 28 weeks. Very premature babies may therefore be susceptible to postnatal infection by CMV from maternal secretions, including breast milk or perinatal transmission from cervical secretions.

Anecdotal evidence suggests that serious illness in some very premature babies is associated with postnatal acquisition of CMV. This possibility has also been suggested in case reports, ${ }^{2}$ and a small case series. ${ }^{34}$ More recently, studies from Germany have shown that CMV in breast milk is transmitted to premature babies and may be associated with disease. ${ }^{56}$

This review will address $(a)$ the evidence for the presence of CMV in breast milk and its transmission to infants, $(b)$ the evidence that postnatally acquired CMV causes disease in premature babies, and $(c)$ the methods available to produce CMV-free breast milk.

See end of article for authors' affiliations

.....................

Correspondence to: Dr Curtis, Department of Paediatrics, University of Melbourne, Royal Children's Hospital Flemington Road, Parkville, VIC 3052, Australia; curtisn@

cryptic.rch.unimelb.edu.au

Accepted 23 April 2002

\section{PRESENCE AND TRANSMISSION OF CMV IN BREAST MILK}

\section{Presence of CMV in breast milk}

The presence of CMV in breast milk was first suggested in the early 1970s when babies who were not congenitally infected were noted to be acquiring CMV late in the first month of life. Historically, perinatal acquisition was attributed to transmission through cervical secretions. However, the absence of CMV in maternal cervical swabs in many cases suggested another source. In 1972, Hayes et al isolated CMV from the breast milk in $27 \%$ of CMV seropositive women. A similar proportion was found by Reynolds et al, ${ }^{8}$ who also found a large increase in the number of infants excreting CMV over the first four months, incriminating infection at or soon after birth and therefore suggesting a maternal source.

CMV has been detected in breast milk in $13-50 \%$ of lactating women. ${ }^{569}{ }^{10}$ This wide range is partly due to the different sensitivities of detection methods, as the proportion was greater when more sensitive methods such as polymerase chain reaction (PCR) were used. ${ }^{561112}$ As would be expected, no CMV seronegative mothers have been found to excrete the virus. When CMV seropositive mothers have been tested specifically, between $32 \%$ and $96 \%$ have been found to excrete CMV in their breast milk. ${ }^{591013}$ The highest figure was recently reported by Hamprecht et al, ${ }^{6}$ who used PCR to detect CMV in both milk whey and cells. This group has previously shown that testing unfractionated milk is less reliable. ${ }^{12}$ The mechanism of CMV reactivation and excretion in the breast milk of lactating women is unknown.

The timing of CMV excretion in breast milk has been studied in some detail. CMV has been isolated from breast milk from one day to nine months after delivery. ${ }^{11}{ }^{14}$ The peak period of excretion was shown in one study to be at three to four weeks. ${ }^{5}$ The latest more detailed study by Hamprecht et $a l^{6}$ showed that CMV DNA appears in the whey within three weeks of delivery in the great majority of CMV positive mothers. DNA was detectable in milk cells slightly later. This study also highlighted the lower sensitivity of viral culture, as virus was not isolated from either milk whey or cells until many days after it was detected by PCR. ${ }^{6}$

\section{Is CMV transmitted in breast milk?}

Babies breast fed by mothers excreting CMV in their milk are commonly asymptomatically infected..$^{59101516}$ In contrast, no formula fed babies are infected in this way. ${ }^{59}$ In the recent study by Hamprecht et al, 33 of 87 (38\%) premature babies breast fed by mothers excreting CMV became infected. CMV was cultured from the babies' urine at a mean of 47 days after delivery.

\section{Is breast milk the only source of transmission?}

At least one study has documented CMV infection in babies whose mothers were apparently not

Abbreviations: CMV, cytomegalovirus; PCR, polymerase chain reaction 
excreting CMV in their breast milk. ${ }^{9}$ Attempts have been made to exclude other possible sources of transmission of CMV. Congenital infection is excluded by the absence of CMV excretion from the baby in the first five to 21 days. ${ }^{56}{ }^{10}$ Excretion from other maternal sites (for example urine, cervical secretions) is excluded by negative maternal samples, or by negative ear swabs from the baby at birth as a surrogate for cervical swabs. ${ }^{56}$ Horizontal transmission by blood is excluded by the use of CMV-free or filtered blood products. ${ }^{6}{ }^{17}$ Horizontal transmission from other people-medical and nursing staff, and visitors such as siblings-is difficult to exclude. Horizontal transmission from maternal saliva is virtually impossible to exclude.

Until recently there has only been circumstantial evidence against transmission from non-breast milk sources. One study, for example, showed that number of siblings (as a marker of potential exposure) was unrelated to CMV infection. ' In another study, infants who were breast fed for longer were more likely to become infected. ${ }^{10}$ Other studies have shown that virus genotype, as defined by restriction enzyme mapping, was the same in mother-baby pairs. ${ }^{6}{ }^{15}$ However, there is now more direct evidence favouring the concept that CMV is transmitted from breast milk rather than cervical secretions. In the study of Hamprecht et al, ${ }^{6}$ the great majority of the babies were born by caesarean section and therefore probably not exposed to cervical secretions. The absence of CMV exposure was confirmed by surface swabs taken immediately after birth. Furthermore, mothers of babies who became infected were much more likely to have virus detectable in their milk by culture (as opposed to PCR only) than those who did not become infected. This suggests that transmission of CMV to the baby was more likely to occur when the viral load in the milk was higher. Moreover, both CMV DNA and virus were detectable significantly earlier in the milk of mothers who transmitted the virus than those who did not.

\section{DISEASE CAUSED BY POSTNATAL CMV ACQUISITION IN PREMATURE BABIES CMV disease in term babies}

Although CMV has been shown to be present in breast milk and transmissible to babies, there is less information about the clinical significance of postnatal primary CMV infection. Anecdotal evidence and case reports suggest that primary CMV infection can cause pneumonitis, even in term infants. ${ }^{30}{ }^{18}$ Stagno et al $l^{3}$ investigated all babies admitted aged between 2 and 12 weeks with pneumonitis and found that $20 \%$ had evidence of CMV infection. However, it is believed that severe disease as a result of CMV acquired postnatally from the mother is uncommon in term babies because they are protected by passively acquired maternal antibodies. ${ }^{19} 20$ Other factors in breast milk, including IgA and anti-viral lipids, may also be protective. In a recent study, vitamin A, monolaurin, and lactoferrin inhibited the growth of CMV in human milk in vitro. ${ }^{21}$ Interestingly, prostaglandin enhanced the growth of CMV at least fourfold.

\section{CMV disease from breast milk in premature babies}

In contrast with babies born at term, very premature babies have an immature immune system and are born before the transfer of the majority of protective immunoglobulins, which occurs after 28 weeks. This may make them more susceptible to CMV disease following primary infection. ${ }^{19}$ In addition, Yeager $e t l^{22}$ found that, even in babies who acquired maternal antibody to CMV, the antibody level fell more rapidly in sick premature babies than would be expected in term infants. In the breast milk studies detailed above, $15-17 \%$ of the babies became unwell at the onset of viral shedding with sepsis-like illnesses, respiratory illnesses, thrombocytopenia, and neutropenia. All of these babies were premature and under 1500 g. ${ }^{5610} \mathrm{~A}$ higher rate of disease was found by Yeager et $\mathrm{al}^{22}: 33 \%$ of babies ( six out of 18) under $1500 \mathrm{~g}$ who acquired CMV postnatally developed hepatomegaly, respiratory symptoms, thrombocytopenia, neutropenia, and/or relative lymphocytosis at the time of first CMV excretion. Of the very premature babies (under 26 weeks gestation) in one study, $80 \%$ had severe sepsis-like symptoms coinciding with infection with CMV. Another study found that 14 of 16 premature babies with postnatal CMV infection developed disease around 4-6 weeks of age consisting of hepatomegaly, sepsis, respiratory deterioration, and atypical and/or absolute lymphocytosis. ${ }^{4}$ Three deaths were directly attributed to this infection.

In the study by Hamprecht et $a l,{ }^{6}$ of the 33 babies who were infected with CMV, 16 (48\%) had symptoms and four of these (25\%) had sepsis-like illnesses consisting of apnoea, bradycardia, and pallor in the absence of bacterial infection. Two of these babies required reintubation and ventilation. In a more detailed assessment of the infants who developed clinical disease from CMV infection, this research group described neutropenia in $88 \%$, thrombocytopenia in $25 \%$, and evidence of liver involvement in $31 \%$. These features coincided with the detection of CMV DNA in blood by PCR. ${ }^{23}$ Putting this in perspective, of the total of 176 babies under $1500 \mathrm{~g}$ in this study, $19 \%$ became infected with CMV from breast milk, $9 \%$ had an illness that may have been related to CMV, and 2\% were severely unwell. Preliminary data from another study have shown lower rates of transmission and clinical disease attributable to $\mathrm{CMV}^{24}$ However, in this study infants of greater gestational age were included and the total number of babies studied was smaller.

\section{Long term sequelae from postnatal CMV infection}

It has previously been suggested that, in contrast with congenital infection, perinatally or postnatally acquired CMV infection does not cause any long term problems. ${ }^{25}{ }^{26}$ However, this view has been challenged by two studies that have assessed outcomes in premature or sick babies with early acquired CMV (in whom congenital infection was excluded). ${ }^{22}{ }^{27}$ In contrast with congenital CMW, perinatal infection was not found to cause sensorineural hearing loss. ${ }^{22}$ However, early onset of CMV excretion was a significant risk factor for severe or moderate neurological impairment at 3 years of age. ${ }^{27}$

\section{CMV-FREE BREAST MILK}

\section{Removal of CMV from breast milk}

If CMV transmission from breast milk is clinically important, then preventing transmission by the production of CMV-free milk is critical. Several methods of killing the virus in milk have been studied, including freezing, pasteurisation, and rapid heating. ${ }^{28-33} \mathrm{~A}$ fundamental issue is whether other beneficial constituents of breast milk, such as immunological and nutritional factors, are adversely affected by the process used to kill CMV. For example, pasteurisation (heating at $62.5^{\circ} \mathrm{C}$ for 30 minutes) is highly effective at removing viable $\mathrm{CMV}$, but will also damage lymphocytes and immunoglobulins in the milk..$^{28-32}$ In contrast, refrigerating and freezing milk are less harmful to the protective constituents in milk, but are much less effective in removing $\mathrm{CMV}^{29-32}$ Our own unpublished investigations have shown that, in some CMV positive breast milk samples, the virus can still be recovered using sensitive culture techniques after up to 10 days of freezing in a domestic $\left(-20^{\circ} \mathrm{C}\right)$ freezer. Despite this, a recent uncontrolled small study suggested that freezing breast milk may be associated with a lower rate of CMV transmission and infection in premature babies. ${ }^{34}$ Treatment for short periods at higher temperature-for example, $72^{\circ} \mathrm{C}$ for five seconds-looks promising for eliminating CMV without having the deleterious effects of pasteurisation, but needs more study. ${ }^{33}$ 
To avoid these problems, an alternative approach is to use milk donated by CMV seronegative mothers. In addition to concerns about other potential infections, however, donated milk is usually mature (with lower protein, nitrogen, and mineral content than milk from mothers of premature babies) and may therefore not meet the specific needs of premature babies. ${ }^{35}$ More innovative methods for CMV removal from or inactivation in maternal milk are therefore needed. There is currently no evidence for the use of prophylactic antiviral agents in either mothers or babies.

\section{SUMMARY}

Evidence from a number of studies shows that CMV is commonly present in breast milk and transmitted to babies. There is increasing evidence that CMV infection acquired postnatally causes serious disease in very premature babies, although the numbers reported to date have been small. Further detailed research is required into the transmission of CMV and consequent long term sequelae. Interventions to remove CMV from the breast milk of CMV seropositive women with premature infants are possible but may damage other important constituents. Changes in practice cannot be recommended until further studies have defined the risk-benefit ratio of such strategies.

\section{Authors' affiliations}

P Bryant, Paediatric Infectious Diseases Unit, Department of General Medicine; Department of Microbiology \& Infectious Diseases, Royal Children's Hospital, Flemington Road, Parkville, VIC 3052, Australia N Curtis, Paediatric Infectious Diseases Unit, Department of Genera Medicine; Department of Microbiology \& Infectious Diseases; Department of Paediatrics, University of Melbourne, Royal Children's Hospital, Parkville, VIC 3052, Australia

C Morley, Department of Neonatal Medicine, Royal Women's \& Children's Hospitals, Carlton, VIC 3053, Australia

$S$ Garland, Department of Microbiology and Infectious Diseases, Royal

Women's \& Children's Hospitals, Carlton, VIC 3053, Australia

\section{REFERENCES}

1 Preece PM, Pearl KN, Peckham CS. Congenital cytomegalovirus infection. Arch Dis Child 1984;59:1 120-6.

2 Richter D, Hampl W, Pohlandt F. Vertical transmission of cytomegalovirus, most probably by breast milk, to an infant with Wiskott-Aldrich syndrome with fatal outcome. Eur J Pediatr 1997; 156:854-5.

3 Stagno S, Brasfield DM, Brown MB, et al. Infant pneumonitis associated with cytomegalovirus, Chlamydia, Pneumocystis, and Ureaplasma: a prospective study. Pediatrics 1981;68:322-9.

4 Ballard RA, Drew WL, Hufnagle KG, et al. Acquired cytomegalovirus infection in preterm infants. American Journal of Diseases of Children 1979; 133:482-5.

5 Vochem M, Hamprecht K, Jahn G, et al. Transmission of cytomegalovirus to preterm infants through breast milk. Pediatr Infect Dis J 1998;17:53-8.

6 Hamprecht K, Maschmann J, Vochem M, et al. Epidemiology of transmission of cytomegalovirus from mother to preterm infant by breastfeeding. Lancet 2001;357:513-18.

7 Hayes K, Danks DM, Gibas H, et al. Cytomegalovirus in human milk. N Engl J Med 1972;287:177-8.
8 Reynolds DW, Stagno S, Hosty TS, et al. Maternal cytomegalovirus excretion and perinatal infection. N Engl J Med 1973;289:1-5.

9 Stagno S, Reynolds DW, Pass RF, et al. Breast milk and the risk of cytomegalovirus infection. N Engl J Med 1980;302:1073-6.

10 Dworsky M, Yow M, Stagno S, et al. Cytomegalovirus infection of breast milk and transmission in infancy. Pediatrics 1983;72:295-9.

11 Boeckh M, Boivin G. Quantitation of cytomegalovirus: methodologic aspects and clinical applications. Clin Microbiol Rev 1998;1 1:533-54.

12 Hamprecht K, Vochem M, Baumeister A, et al. Detection of cytomegaloviral DNA in human milk cells and cell free milk whey by nested PCR. J Virol Methods 1998;70:167-76.

13 Ahlfors K, Ivarsson SA. Cytomegalovirus in breast milk of Swedish milk donors. Scand J Infect Dis 1985;17:1 1-13.

14 Asanuma H, Numazaki K, Nagata N, et al. Role of milk whey in the transmission of human cytomegalovirus infection by breast milk. Microbiol Immunol 1996;40:201-4.

15 Peckham CS, Johnson C, Ades A, et al. Early acquisition of cytomegalovirus infection. Arch Dis Child 1987:62:780-5.

16 Minamishima I, Ueda K, Minematsu T, et al. Role of breast milk in acquisition of cytomegalovirus infection. Microbiol Immunol 1994; 38:549-52.

17 de Cates CR, Gray J, Roberton NR, et al. Acquisition of cyłomegalovirus infection by premature neonates. J Infect 1994;28:25-30.

18 Brasfield DM, Stagno S, Whitley RJ, et al. Infant pneumonitis associated with cytomegalovirus, Chlamydia, Pneumocystis, and Ureaplasma: follow-up. Pediatrics 1987;79:76-83.

19 Yeager AS, Grumet FC, Hafleigh EB, et al. Prevention of transfusion-acquired cytomegalovirus infections in newborn infants. $J$ Pediatr 1981;98:281-7

20 Alford CA, Stagno S, Pass RF, et al. Congenital and perinatal cytomegalovirus infections. Rev Infect Dis 1990;12(suppl 7):S745-53.

21 Clarke NM, May JT. Effect of antimicrobial factors in human milk on rhinoviruses and milk-borne cytomegalovirus in vitro. J Med Microbiol 2000;49:719-23

22 Yeager AS, Palumbo PE, Malachowski N, et al. Sequelae of maternally derived cytomegalovirus infections in premature infants. J Pediatr 1983;102:918-22.

23 Maschmann J. Cytomegalovirus infection of extremely low-birth weight infants via breast milk. Clin Infect Dis 2001;33:1998-2003

24 Mosca F, Pugni L, Barbi $M$, et al. Transmission of cytomegalovirus. Lancet 2001;357:1800.

25 Kumar ML, Nankervis GA, Jacobs IB, et al. Congenital and postnatally acquired cytomegalovirus infections: long-term follow-up. J Pediatr 1984; 104:674-9.

26 Granstrom $M$, Leinikki $P$, Santavuori $P$, et al. Perinatal cytomegalovirus infection in man. Arch Dis Child 1977;52:354-9.

27 Paryani SG, Yeager AS, Hosford-Dunn H, et al. Sequelae of acquired cytomegalovirus infection in premature and sick term infants. J Pediatr 1985; 107:451-6.

28 Biorksten B, Burman LG, De Chateau P, et al. Collecting and banking human milk: to heat or not to heat? BM 1980;281:765-9.

29 Liebhaber M, Lewiston NJ, Asquith MT, et al. Alterations of lymphocytes and of antibody content of human milk after processing. J Pediatr 1977:91:897-900.

30 Welsh JK, Arsenakis M, Coelen RJ, et al. Effect of antiviral lipids, heat, and freezing on the activity of viruses in human milk. J Infect Dis $1979 ; 140: 322-8$

31 Friis $\mathbf{H}$, Andersen HK. Rate of inactivation of cytomegalovirus in raw banked milk during storage at -20 degrees $C$ and pasteurisation. British Medical Journal Clinical Research Edition 1982;285:1604-5.

32 Dworsky M, Stagno S, Pass RF, et al. Persistence of cytomegalovirus in human milk after storage. J Pediatr 1982;101:440-3.

33 Goldblum RM, Dill CW, Albrecht TB, et al. Rapid high-temperature treatment of human milk. J Pediatr 1984;104:380-5.

34 Sharland M, Khare M, Bedford-Russell A. Prevention of postnatal cytomegalovirus infection in preterm infants. Arch Dis Child Fetal Neonatal Ed 2002;86:F140.

35 Anonymous. American Academy of Pediatrics. Committee on Nutrition. Human milk banking. Pediatrics 1980;65:854-7. 